\title{
Isolated abducens nerve palsy associated with subarachnoid hemorrhage: a localizing sign of ruptured posterior inferior cerebellar artery aneurysms
}

\author{
Jan-Karl Burkhardt, MD, Ethan A. Winkler, MD, PhD, George F. Lasker, MD, PhD, John K. Yue, BA, \\ and Michael T. Lawton, MD
}

Department of Neurological Surgery, University of California, San Francisco, California

OBJECTIVE Compressive cranial nerve syndromes can be useful bedside clues to the diagnosis of an enlarging intracranial aneurysm and can also guide subsequent evaluation, as with an acute oculomotor nerve (cranial nerve [CN] III) palsy that is presumed to be a posterior communicating artery aneurysm and a surgical emergency until proven otherwise. The CN VI has a short cisternal segment from the pontomedullary sulcus to Dorello's canal, remote from most PICA aneurysms but in the hemodynamic pathway of a rupturing PICA aneurysm that projects toward Dorello's canal. The authors describe a cranial nerve syndrome for posterior inferior cerebellar artery (PICA) aneurysms that associates subarachnoid hemorrhage (SAH) and an isolated abducens nerve (CN VI) palsy.

METHODS Clinical and radiological data from 106 surgical patients with PICA aneurysms (66 ruptured and 40 unruptured) were retrospectively reviewed. Data from a group of 174 patients with other aneurysmal SAH (aSAH) were analyzed in a similar manner to control for nonspecific effects of SAH. Univariate statistical analysis compared incidence and risk factors associated with CN VI palsy in subarachnoid hemorrhage.

RESULTS Overall, 13 (4.6\%) of 280 patients had CN VI palsy at presentation, and all of them had ruptured aneurysms (representing $13[5.4 \%]$ of the 240 cases of ruptured aneurysms). CN VI palsies were observed in 12 patients with ruptured PICA aneurysms (12/66 [18.1\%]) and 1 patient with other aSAH (1/174 [0.1\%], $p<0.0001)$. PICA aneurysm location in ruptured aneurysms was an independent predictor for $\mathrm{CN}$ VI palsy on multivariate analysis $(p=0.001)$. PICA aneurysm size was not significantly different in patients with or without CN VI palsy (average size $4.4 \mathrm{~mm}$ and $5.2 \mathrm{~mm}$, respectively). Within the PICA aneurysm cohort, modified Fisher grade $(p=0.011)$ and presence of a thick cisternal SAH (modified Fisher Grades 3 and 4$)(p=0.003$ ) were predictors of CN VI palsy. In all patients with ruptured PICA aneurysms and CN VI palsy, dome projection and presumed direction of rupture were directed toward the ipsilateral and/ or contralateral Dorello's canal, in agreement with laterality of the $\mathrm{CN}$ palsy. In patients with bilateral CN VI palsies, a medial projection with extensive subarachnoid blood was observed near bilateral canals.

CONCLUSIONS This study establishes a localizing connection between an isolated CN VI palsy, SAH, and an underlying ruptured PICA aneurysm. CN VI palsy is an important clinical sign in aSAH and when present on initial clinical presentation may be assumed to be due to ruptured PICA aneurysms until proven otherwise. The deficit may be ipsilateral, contralateral, or bilateral and is determined by the direction of the aneurysm dome projection and extent of subarachnoid bleeding toward Dorello's canal, rather than by direct compression.

https://thejns.org/doi/abs/10.3171/2017.2.JNS162951

KEY WORDS abducens nerve palsy; CN VI palsy; posterior inferior cerebellar artery aneurysms; horizontal diplopia; cranial nerve syndrome; vascular disorders

$\mathrm{W}$ HILE the majority of intracranial aneurysms present with subarachnoid hemorrhage (SAH) or as an incidental finding on neurological imaging, a small percentage of aneurysms enlarge and pres- ent with isolated cranial nerve palsies from compression of the nerve. ${ }^{4,8}$ Oculomotor nerve (cranial nerve $[\mathrm{CN}]$ III) palsy is the most common, seen in association with posterior communicating artery (PCoA) aneurysms that

ABBREVIATIONS aSAH = aneurysmal SAH; $\mathrm{CI}=$ confidence interval; $\mathrm{CN}=$ cranial nerve; $\mathrm{EVD}=$ external ventricular drain; $\mathrm{ICA}=$ internal carotid artery; $\mathrm{OR}=$ odds ratio; PCOA = posterior communicating artery; PICA = posterior inferior cerebellar artery; $\mathrm{SAH}=$ subarachnoid hemorrhage.

SUBMITTED November 26, 2016. ACCEPTED February 24, 2017.

INCLUDE WHEN CITING Published online September 1, 2017; DOI: 10.3171/2017.2.JNS162951. 
project into the nerve that parallels the parent artery. ${ }^{2,4,18}$ Classic clinical signs consist of ipsilateral pupillary dilation (from compression of pupillomotor fibers); inhibition of ipsilateral medial, upward, and downward gaze; and preservation of lateral gaze. Visual field deficits are observed in association with ophthalmic artery aneurysms that compress the optic nerve (CN II), specifically those that lift the nerve from below and bend its superolateral fibers against the falciform ligament, producing a quadrantanopia in the inferomedial or nasal field. The optic nerve can also be compressed by anterior communicating artery aneurysms that project inferiorly or by large and giant aneurysms of the internal carotid artery (ICA). ${ }^{11,14,16}$ Cavernous ICA aneurysms cause an indolent ophthalmoplegia from progressive compression of oculomotor, trochlear (CN IV), and abducens (CN VI) nerves, affecting all 3 nerves as they course through the cavernous sinus. ${ }^{3,8}$ Rarely, distal anterior inferior cerebellar artery aneurysms that project into the internal acoustic meatus can cause facial weakness or hearing loss from compression of the facial (CN VII) and vestibulocochlear (CN VIII) nerves. ${ }^{10,17}$

Cranial nerve syndromes can be useful bedside clues to the diagnosis of an intracranial aneurysm and also guide subsequent evaluation. For example, an acute CN III palsy is presumed to be a PCoA aneurysm until proven otherwise, and indicates urgent angiography and treatment. Additional cranial nerve syndromes would increase the clinicians' diagnostic acumen and inform aneurysm management, and we happened upon one for posterior inferior cerebellar artery (PICA) aneurysms, after noticing on numerous occasions the presence of an isolated abducens nerve palsy associated with SAH. The abducens nerve has a short cisternal segment from its ventral exit from the pontomedullary sulcus to its entry into Dorello's canal, ${ }^{6,9}$ which is remote from most PICA aneurysms. However, the nerve lies in the hemodynamic pathway of a rupturing PICA aneurysm that projects toward Dorello's canal. We hypothesized that an isolated $\mathrm{CN}$ VI palsy associated with aneurysmal SAH (aSAH) is likely caused by hemodynamic injury of the nerve at the time of rupture, rather than a direct compressive effect as observed with other aneurysms, and might serve as a localizing sign for PICA aneurysm location. CN VI palsies have been associated with PICA aneurysms in case reports, but a systematic analysis of this clinical sign has not been reported previously. ${ }^{7,12,13,15}$

\section{Methods \\ Inclusion Criteria}

This study was approved by the University of California, San Francisco, institutional review board and performed in compliance with Health Insurance Portability and Accountability Act regulations. A retrospective review of all aneurysms treated microsurgically by the senior author (M.T.L.) between January 1998 and September 2016 identified 106 patients with ruptured $(n=66)$ and unruptured $(\mathrm{n}=40)$ PICA aneurysms, as well as a control group of patients with SAH from non-PICA aneurysms (n = 174) between September 2013 and September 2016.
TABLE 1. Characteristics of patients with ruptured and unruptured PICA aneurysms

\begin{tabular}{|c|c|c|c|c|}
\hline Characteristic & $\begin{array}{c}\text { PICA } \\
\text { (106 pts) }\end{array}$ & $\begin{array}{l}\text { uPICA } \\
\text { (40 pts) }\end{array}$ & $\begin{array}{l}\text { rPICA } \\
\text { (66 pts) }\end{array}$ & $\begin{array}{c}p \\
\text { Value }\end{array}$ \\
\hline Sex & & & & 0.65 \\
\hline Male & $28(74)$ & $12(30)$ & $16(24)$ & \\
\hline Female & $78(26)$ & $28(70)$ & $50(76)$ & \\
\hline Age, yrs & & & & 0.14 \\
\hline Mean & 54.6 & 57.3 & 53 & \\
\hline Range & $24-86$ & $27-86$ & $24-85$ & \\
\hline Aneurysm size, mm & & & & 0.36 \\
\hline Mean & 5.6 & 6.5 & 5 & \\
\hline Range & $2-20$ & $2-20$ & $2-14$ & \\
\hline Saccular aneurysm shape & $59(56)$ & $18(45)$ & & \\
\hline Aneurysm location & & & & 0.43 \\
\hline$p_{1}$ & $63(59)$ & $25(63)$ & $38(58)$ & \\
\hline $\mathrm{p}_{2}$ & $25(24)$ & $8(20)$ & $17(26)$ & \\
\hline$p_{3}$ & $12(11)$ & $4(10)$ & $8(12)$ & \\
\hline $\mathrm{p}_{4}$ & $6(6)$ & $3(7)$ & $3(4)$ & \\
\hline Surgical treatment modality & & & & 0.84 \\
\hline Clipping & $64(60)$ & $25(62)$ & $42(64)$ & \\
\hline Other & $42(40)$ & $15(38)$ & $24(36)$ & \\
\hline CN VI palsy & $12(11)$ & $0(0)$ & $12(18)$ & 0.003 \\
\hline
\end{tabular}

Pts = patients; rPICA = ruptured PICA (aneurysm); uPICA = unruptured PICA (aneurysm).

Values are number of patients or cases (\%) unless otherwise indicated. Boldface type indicates statistical significance.

\section{Clinical and Radiological Data}

Clinical data, including age, sex, Hunt and Hess clinical grade, and cranial nerve deficits, were collected. Radiological data, including aneurysm size, segmental location of PICA aneurysms $\left(\mathrm{p}_{1}-\mathrm{p}_{4}\right)$, aneurysm morphology (saccular vs fusiform), and direction of aneurysm projection, were collected for all aneurysms. For SAH patients, modified Fisher score, presence of a thick cisternal clot, hydrocephalus, and the need for an external ventricular drain (EVD) were recorded. All patients included in this study had their aneurysms treated microsurgically.

\section{Statistical Testing}

Statistical analysis was performed using SPSS version 22 (IBM Corp.). Continuous variables are presented as mean with standard deviation and/or range when appropriate. Comparisons between groups were performed using analysis of variance (ANOVA) for continuous parameters and the chi-square test for categorical parameters. The Fisher exact test was used for categorical parameters with group counts of less than 5. Univariate logistic regression was performed using demographic and clinical predictors with abducens nerve palsy as the dependent variable. Significant univariate predictors were entered into multivariable regression for abducens nerve palsy. Odds ratios (ORs) and associated 95\% confidence intervals (CIs) are reported for regression analyses. Statistical significance was established $\mathrm{p}=0.05$. 
TABLE 2. Characteristics of patients with ruptured PICA aneurysms with and without CN VI palsy

\begin{tabular}{|c|c|c|c|c|}
\hline Characteristic & $\begin{array}{c}\text { All } \\
\text { rPICA } \\
\text { (66 pts) }\end{array}$ & $\begin{array}{l}\text { No CN } \\
\text { VI Palsy } \\
\text { (54 pts) }\end{array}$ & $\begin{array}{c}\text { CN VI } \\
\text { Palsy } \\
\text { (12 pts) }\end{array}$ & $\begin{array}{c}p \\
\text { Value }\end{array}$ \\
\hline Sex & & & & 0.95 \\
\hline Male & $16(24)$ & $13(24)$ & $3(25)$ & \\
\hline Female & $50(76)$ & $41(76)$ & $9(75)$ & \\
\hline Age, yrs & & & & 0.44 \\
\hline Mean & 53 & 53.5 & 50.4 & \\
\hline Range & $24-85$ & $24-85$ & $34-72$ & \\
\hline Aneurysm size, $\mathrm{mm}$ & & & & 0.52 \\
\hline Mean & 5 & 5.2 & 4.4 & \\
\hline Range & $2-14$ & $2-14$ & $3-8$ & \\
\hline Saccular aneurysm shape & $41(62)$ & $35(70)$ & $6(50)$ & 0.14 \\
\hline Aneurysm location & & & & 0.35 \\
\hline$p_{1}$ & $38(58)$ & $30(56)$ & $8(66)$ & \\
\hline $\mathrm{p}_{2}$ & $17(26)$ & $15(28)$ & $2(17)$ & \\
\hline$p_{3}$ & $8(12)$ & $6(11)$ & $2(17)$ & \\
\hline $\mathrm{p}_{4}$ & $3(4)$ & $3(5)$ & $0(0)$ & \\
\hline Surgical treatment modality & & & & 0.30 \\
\hline Clipping & $42(64)$ & $36(67)$ & $6(50)$ & \\
\hline Other & $24(36)$ & $18(33)$ & $6(50)$ & \\
\hline $\mathrm{H} \& \mathrm{H}$ grade & & & & 0.46 \\
\hline I & $3(5)$ & $3(6)$ & $0(0)$ & \\
\hline II & $23(35)$ & $18(33)$ & $5(42)$ & \\
\hline III & $23(35)$ & $18(33)$ & $5(42)$ & \\
\hline IV & $12(18)$ & $10(19)$ & $2(16)$ & \\
\hline V & $5(7)$ & $5(9)$ & $0(0)$ & \\
\hline mRS score at LFU & & & & 0.18 \\
\hline 0 & $0(0)$ & $0(0)$ & $0(0)$ & \\
\hline 1 & $9(14)$ & $7(13)$ & $2(17)$ & \\
\hline 2 & $31(47)$ & $23(43)$ & $8(67)$ & \\
\hline 3 & $10(15)$ & $8(15)$ & $2(16)$ & \\
\hline 4 & $11(17)$ & $11(20)$ & $0(0)$ & \\
\hline 5 & $3(4)$ & $3(5)$ & $0(0)$ & \\
\hline 6 & $2(3)$ & $2(4)$ & $0(0)$ & \\
\hline Modified Fisher grade & & & & 0.011 \\
\hline 0 & $2(3)$ & $2(4)$ & $0(0)$ & \\
\hline 1 & $3(4)$ & $3(6)$ & $0(0)$ & \\
\hline 2 & $19(29)$ & $19(35)$ & $0(0)$ & \\
\hline 3 & $1(2)$ & $1(2)$ & $0(0)$ & \\
\hline 4 & $41(62)$ & $29(53)$ & $12(100)$ & \\
\hline SAH clot & $42(64)$ & $30(56)$ & $12(100)$ & 0.003 \\
\hline Hydrocephalus & $41(62)$ & $34(63)$ & $7(58)$ & 0.75 \\
\hline EVD placement & $5(62)$ & $33(61)$ & $8(67)$ & 0.52 \\
\hline
\end{tabular}

$\mathrm{H} \& \mathrm{H}=$ Hunt and Hess; $\mathrm{LFU}=$ last follow-up; $m R S=$ modified Rankin Scale. Values are number of patients or cases (\%) unless otherwise indicated. Boldface type indicates statistical significance.
TABLE 3. Characteristics of patients with aSAH stratified by ruptured PICA and other intracranial aneurysms

\begin{tabular}{|c|c|c|c|c|}
\hline Characteristic & $\begin{array}{c}\text { All aSAH } \\
(240 \text { pts) }\end{array}$ & $\begin{array}{c}\text { rPICA } \\
\text { (66 pts) }\end{array}$ & $\begin{array}{c}\text { Other aSAH } \\
\text { (174 pts) }\end{array}$ & $\begin{array}{c}p \\
\text { Value }\end{array}$ \\
\hline Sex & & & & 0.231 \\
\hline Male & $72(30)$ & $16(24)$ & $56(32)$ & \\
\hline Female & $168(70)$ & $50(76)$ & $118(68)$ & \\
\hline Age, yrs & & & & 0.027 \\
\hline Mean & 56.1 & 53 & 57.3 & \\
\hline SD & 13.4 & 12.9 & 13.5 & \\
\hline Range & $17-88$ & $24-85$ & $17-88$ & \\
\hline $\mathrm{H} \& \mathrm{H}$ grade & & & & 0.316 \\
\hline I & $21(9)$ & $3(5)$ & $18(10)$ & \\
\hline II & $86(36)$ & $23(35)$ & $63(36)$ & \\
\hline III & $67(28)$ & $23(35)$ & $44(25)$ & \\
\hline IV & $39(16)$ & $12(18)$ & $27(16)$ & \\
\hline V & $27(11)$ & $5(7)$ & $22(13)$ & \\
\hline Modified Fisher grade & & & & $<0.0001$ \\
\hline 1 & $11(5)$ & $5(7)$ & $6(3)$ & \\
\hline 2 & $36(15)$ & $19(29)$ & $17(10)$ & \\
\hline 3 & $55(23)$ & $1(2)$ & $54(31)$ & \\
\hline 4 & $138(58)$ & $41(62)$ & $97(56)$ & \\
\hline SAH clot & $193(80)$ & $42(64)$ & $151(87)$ & $<0.0001$ \\
\hline Hydrocephalus & $128(53)$ & $41(62)$ & $87(50)$ & 0.093 \\
\hline EVD placement & $128(53)$ & $41(62)$ & $87(50)$ & 0.093 \\
\hline CN VI palsy & $13(8)$ & $12(18)$ & $1(1)$ & $<0.0001$ \\
\hline
\end{tabular}

Values are number of patients or cases (\%) unless otherwise indicated. Boldface type indicates statistical significance.

\section{Results}

Overall, 106 patients with 106 PICA aneurysms were included in this analysis (40 with unruptured aneurysms and 66 with ruptured aneurysms). Patient demographics and aneurysm characteristics were comparable between the ruptured and unruptured PICA aneurysm groups (Table 1), except that all abducens nerve palsies were observed in patients with ruptured PICA aneurysms (12 of 66 patients, incidence of $18.1 \%, \mathrm{p}=0.003)$. All abducens nerve palsies were present preoperatively, and none was recorded as a new postoperative deficit.

Among the 66 patients with ruptured PICA aneurysms, patient demographics and aneurysm characteristics were comparable between those with and without abducens nerve palsy, except for modified Fisher grade $(\mathrm{p}=0.011)$ and presence of a thick cisternal SAH (modified Fisher Grades 3 and 4) (100\% and 56\%, respectively; $p=0.003$ ), suggesting more severe aneurysm ruptures in patients with CN VI palsy (Table 2).

The patient demographic and aneurysm characteristics in the comparison group of 174 patients with ruptured non-PICA aneurysms were similar to those in the group of 66 patients with ruptured PICA aneurysms. However, only 1 patient in the comparison group had an abducens nerve palsy $(<1 \%$ incidence with other aSAH, as compared with 
TABLE 4. Univariate and multivariate statistical modeling of predictors of an abducens nerve palsy in patients with aSAH

\begin{tabular}{lcccc}
\hline Predictor & $\begin{array}{c}\text { Univariate OR } \\
(95 \% \mathrm{Cl})\end{array}$ & $\begin{array}{c}\mathrm{p} \\
\text { Value }\end{array}$ & $\begin{array}{c}\text { Multivariable OR } \\
(95 \% \mathrm{Cl})\end{array}$ & $\begin{array}{c}\mathrm{p} \\
\text { Value }\end{array}$ \\
\hline Age & $0.96(0.92-0.99)$ & $\mathbf{0 . 0 4 6}$ & $0.93(0.93-1.02)$ & 0.279 \\
\hline Sex & $1.46(0.39-5.45)$ & 0.577 & - & - \\
\hline $\mathrm{H} \& \mathrm{H}$ & $0.93(0.57-1.53)$ & 0.782 & - & - \\
\hline Fisher & $6.37(0.98-41.25)$ & 0.052 & $4.33(0.97-19.29)$ & 0.055 \\
\hline IVH & $4.82(0.61-37.78)$ & 0.135 & - & - \\
\hline EVD & $1.43(0.45-4.49)$ & 0.544 & - & - \\
\hline rPICA & $38.44(4.89-302.46)$ & $\mathbf{0 . 0 0 1}$ & $36.60(4.51-296.57)$ & $\mathbf{0 . 0 0 1}$ \\
\hline
\end{tabular}

$\mathrm{IVH}=$ intraventricular hemorrhage.

Boldface type indicates statistical significance.

an $18.1 \%$ incidence with ruptured PICA aneurysms; $\mathrm{p}<$ 0.0001) (Table 3), suggesting that abducens nerve palsies were associated with PICA aneurysm rupture rather than aneurysm rupture in general. Patients with ruptured PICA aneurysms had a lower incidence of thick cisternal SAH $(p<0.0001)$ and lower modified Fisher grades $(p<0.0001)$ than patients with SAH due to rupture of non-PICA aneurysms, indicating less severe aneurysm ruptures in PICA aneurysm patients and suggesting that severity of SAH in general was not responsible for CN VI palsy (Table 3). Multivariate analysis confirmed PICA aneurysm location as the only independent predictor for CN VI palsy (OR $36.6, \mathrm{p}=0.001)($ Table 4).

The segmental location of the PICA aneurysm and the direction of the aneurysm dome projection affected abducens nerve palsies (Table 5). Four abducens nerve palsies were ipsilateral to the ruptured PICA aneurysm (Fig. 1), 2 palsies were contralateral to the aneurysm (Fig. 2), and 6 palsies were bilateral (Fig. 3). Four of the 6 patients with bilateral CN VI palsies had proximal aneurysms $\left(\mathrm{p}_{1}\right.$ and $\mathrm{p}_{2}$ PICA segments) projecting medially and superiorly; in the other 2 cases, the aneurysms were in the $\mathrm{p}_{1}$ segment, but information on the direction of projection was not available. Patients with unilateral CN VI palsies had either medial-superior aneurysm projection (present in 2 patients with a contralateral palsy), lateral-superior aneurysm projection (in 3 patients with an ipsilateral palsy), or no projection (in 1 patient with a fusiform aneurysm and an ipsilateral CN VI palsy) (Table 5). In all cases of unilateral CN VI palsy, irrespective of whether the palsy was contralateral or ipsilateral to the aneurysm, the axis of the aneurysm (defined by a line from the midpoint of the aneurysm neck to the apex of the aneurysm dome) was in line with the affected Dorello's canal, suggesting the hemodynamic pathway of the jet of ruptured blood.

All patients were operated on via a far-lateral approach with suboccipital craniotomy, C-1 laminectomy, and partial condylectomy. Direct clipping of the aneurysm was possible in 8 of 12 patients, and aneurysm trapping and PICA reimplantation was performed in 4 of 12 patients. Postoperative angiography confirmed complete aneurysm occlusion in all 12 patients, and patency of all 4 reimplanted PICAs. CN VI palsies improved in 10 PICA aneurysm patients at late follow-up (mean duration, 28.3 months), with 5 complete recoveries and 5 partial recoveries. Two patients were lost to late follow-up. Neurological outcome at last follow-up in the CN VI palsy group was favorable in $83 \%$ of cases (mRS Scores 0-2 in 10 of 12 patients, including the 2 patients lost to follow-up, who both had an $\mathrm{mRS}$ score of 2 at discharge). Two patients had a mRS scores of 3 at late follow-up.

When compared with the outcome in the group of patients with ruptured PICA aneurysms without CN VI palsy, the mRS outcome in the group with ruptured PICA aneurysms with $\mathrm{CN}$ VI palsy was not dependent on the CN VI palsy $(p=0.18)$, but showed a correlation to the initial Hunt and Hess grade $(p<0.001)$. The proportion of favorable outcome (mRS Scores 0-2) had a tendency to be higher in the CN VI palsy group than in the group with ruptured PICA aneurysms without CN VI palsy (10/12

TABLE 5. Patients with a PICA aneurysm and CN VI palsy

\begin{tabular}{|c|c|c|c|c|c|c|c|c|c|}
\hline $\begin{array}{l}\text { Case } \\
\text { No. }\end{array}$ & $\begin{array}{c}\text { Age (yrs) } \\
\text { Sex }\end{array}$ & $\begin{array}{c}\text { PICA } \\
\text { Segment }\end{array}$ & $\begin{array}{l}\mathrm{H} \& \mathrm{H} \\
\text { Grade }\end{array}$ & $\begin{array}{c}\text { mFisher } \\
\text { Grade }\end{array}$ & $\begin{array}{l}\text { Aneurysm } \\
\text { Size (mm) }\end{array}$ & $\begin{array}{l}\text { Aneurysm } \\
\text { Morphology }\end{array}$ & $\begin{array}{l}\text { Aneurysm } \\
\text { Projection }\end{array}$ & $\begin{array}{l}\text { CN VI } \\
\text { Palsy }\end{array}$ & Treatment \\
\hline 1 & $52, \mathrm{M}$ & $\mathrm{p}_{2}$ & II & 4 & 3 & Fusiform & Medial-superior & Bilateral & Clipping \\
\hline 2 & $47, \mathrm{~F}$ & $p_{1}$ & II & 4 & 3 & Saccular & NA & Bilateral & Clipping \\
\hline 3 & $49, \mathrm{~F}$ & $p_{1}$ & III & 4 & 8 & Saccular & Lateral-superior & Ipsilateral & Clipping \\
\hline 4 & $52, \mathrm{M}$ & $p_{1}$ & III & 4 & 3 & Fusiform & Medial-superior & Contralateral & PICA reimplantation, trapping \\
\hline 5 & $43, \mathrm{M}$ & $p_{3}$ & III & 4 & 3 & Fusiform & No projection & Ipsilateral & PICA reimplantation, trapping \\
\hline $6^{*}$ & $46, F$ & $p_{1}$ & II & 4 & 5 & Saccular & Medial-superior & Bilateral & PICA reimplantation, trapping \\
\hline $7^{*}$ & $49, \mathrm{~F}$ & $p_{3}$ & II & 4 & 6 & Saccular & Medial-inferior & Contralateral & Clipping \\
\hline 8 & $54, \mathrm{~F}$ & $p_{1}$ & IV & 4 & 6 & Fusiform & Medial-superior & Bilateral & PICA reimplantation, trapping \\
\hline $9^{*}$ & $65, F$ & $p_{1}$ & II & 4 & 4 & Saccular & Lateral-superior & Ipsilateral & Clipping \\
\hline 10 & $34, F$ & $\mathrm{p}_{2}$ & III & 4 & 3 & Saccular & Lateral-superior & Ipsilateral & Clipping \\
\hline 11 & $72, \mathrm{~F}$ & $p_{1}$ & III & 4 & 3 & Saccular & Medial-superior & Bilateral & Clipping \\
\hline 12 & $42, \mathrm{~F}$ & $p_{1}$ & IV & 4 & 5 & Saccular & NA & Bilateral & Clipping \\
\hline
\end{tabular}

mFisher = modified Fisher; $\mathrm{NA}=$ not available due to retrospective chart review

* Cases presented in this paper. 

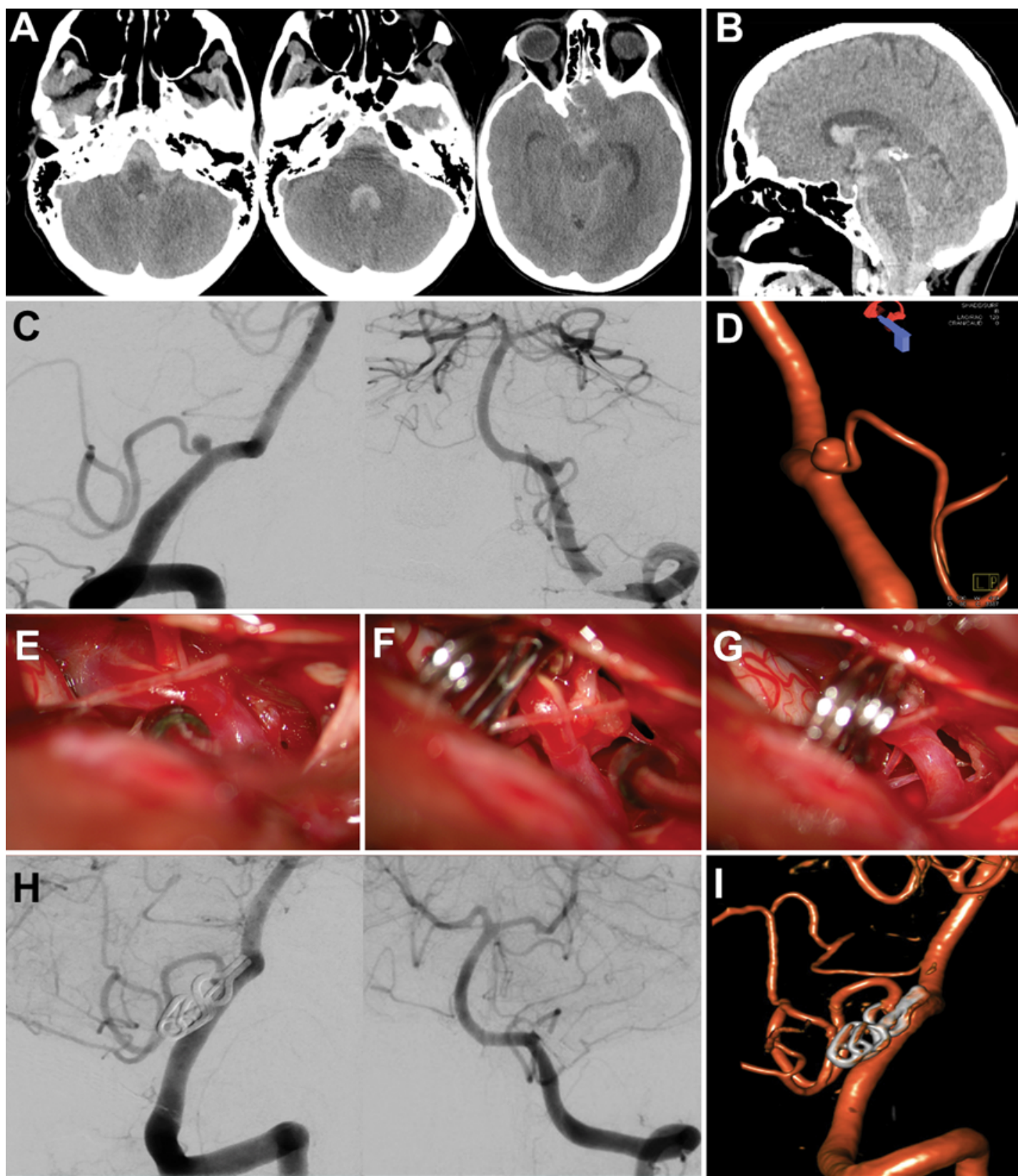

FIG. 1. Case 9. This 65-year-old woman presented with severe headache, diplopia, nausea, and vomiting, and a complete left CN VI palsy was observed on neurological examination (Hunt and Hess Grade II). SAH was diagnosed on CT scan (modified Fisher Grade 4) (A and B), and a ruptured 4-mm left PICA aneurysm was seen angiographically, with its dome projecting superolaterally toward the ipsilateral Dorello's canal (C and D). Through a left mini far-lateral craniotomy, the aneurysm was clipped using a straight fenestrated clip over the PICA origin and a second straight clip through a small tag in the fenestration to complete the closure (E-G). Indocyanine green (ICG) video angiography demonstrated PICA patency and no further filling of the aneurysm. Postoperative angiography confirmed complete occlusion of the aneurysm ( $\mathrm{H}$ and I). The patient recovered well from surgery, was discharged home 10 days after admission, and had complete resolution of the left CN VI palsy at the 6-week follow-up evaluation (mRS Score 1).

[83\%] vs 31/54 [57\%]), but the difference was not statistically significant $(\mathrm{p}=0.11)$.

\section{Discussion}

Clinical signs that are apparent on physical examination at the bedside improve the diagnostic acumen of the neurosurgeon and can guide subsequent diagnostic evaluation and treatment. In this report, we establish a localizing connection between an isolated abducens nerve palsy, SAH, and an underlying ruptured PICA aneurysm. Although anecdotal case reports have described CN VI palsies associated with ruptured PICA aneurysms, $, 5,5,12$, ${ }^{13,15}$ our study is the first to demonstrate that this clinical 

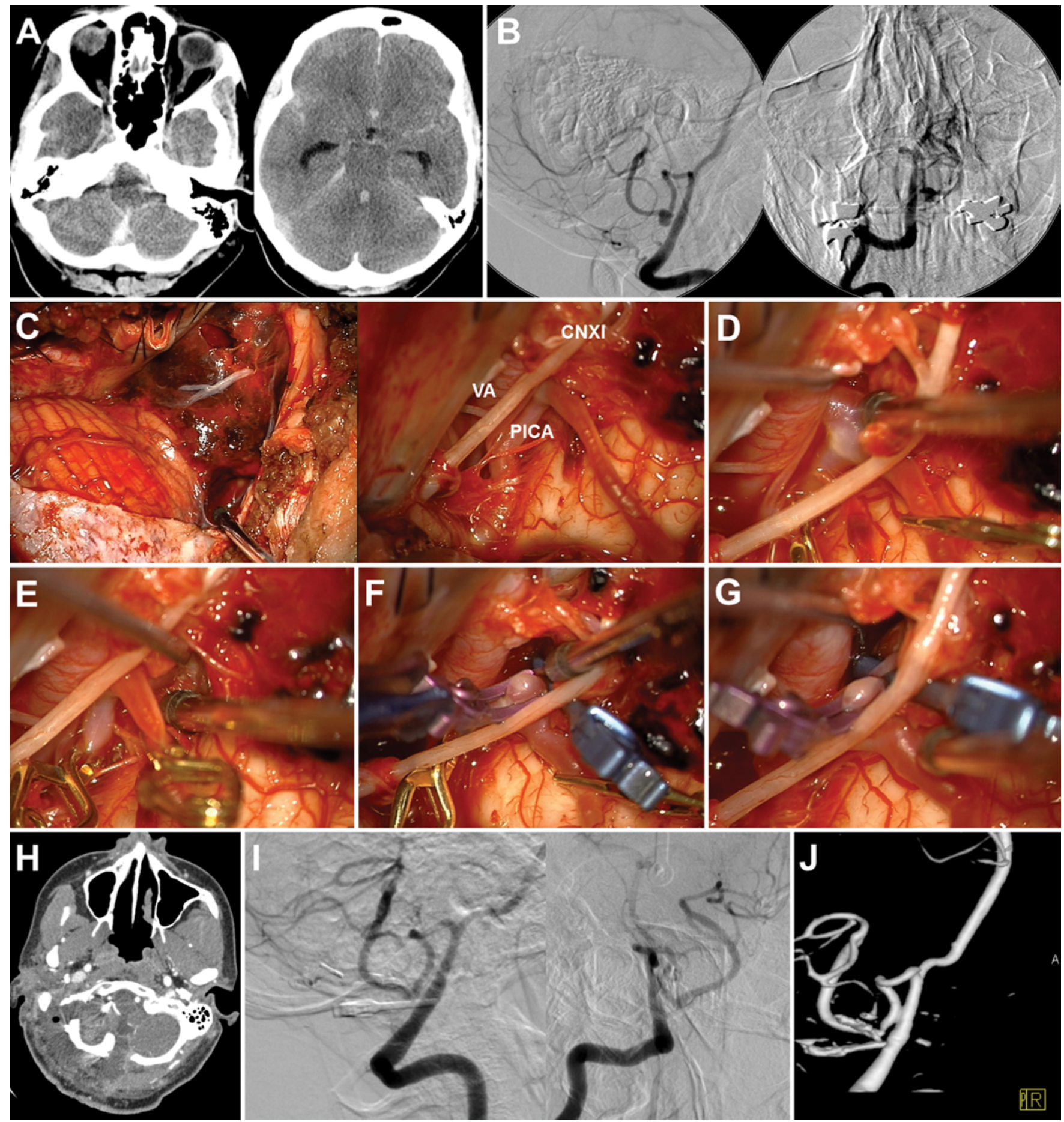

FIG. 2. Case 7. This 49-year-old woman presented with severe headaches (of 2 days' duration), gait disturbances, double vision with left lateral gaze, and a left CN VI palsy was observed (Hunt and Hess Grade II). CT showed SAH (modified Fisher Grade 4; A) and angiography revealed a 6-mm right bilobulated PICA aneurysm (B). The larger lobule projected inferiorly, and the smaller lobule projected medially to the contralateral side. Through a right far-lateral approach, a clot within the cisterna magna was evacuated, the vertebral artery (VA) was exposed for proximal control of the aneurysm, and the PICA was dissected from distal to proximal in the cerebellomedullary fissure to the aneurysm (C and D). With temporary clips placed on the PICA proximal and distal to the aneurysm (E), the aneurysm's larger lobule was clipped with a straight clip and the smaller lobule was clipped with a curved clip (F and G). ICG angiography confirmed PICA patency with no residual filling of the aneurysm. Postoperative angiography confirmed complete occlusion of the aneurysm $(\mathrm{H}-\mathrm{J})$. The patient recovered well from surgery, was discharged 17 days after admission, and demonstrated partial recovery of her contralateral CN VI function at the 6-week follow-up evaluation (mRS Score 2). 

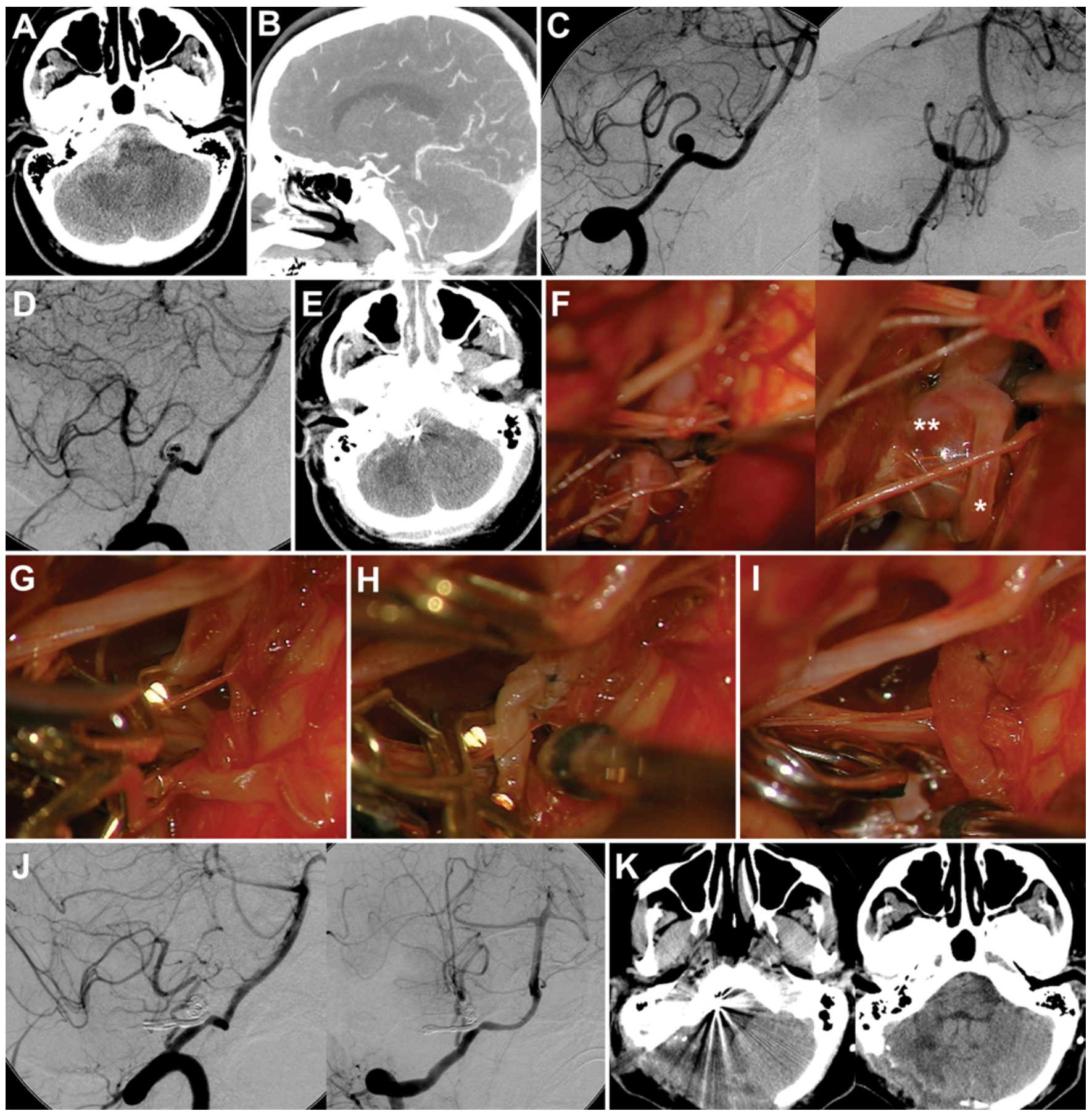

FIG. 3. Case 6. This 46-year-old woman presented with sudden-onset, severe headache, neck pain, nuchal rigidity, dizziness, and nausea. Bilateral CN VI palsies were observed on neurological examination (Hunt and Hess Grade II). CT (A and B) and catheter angiography (C) showed SAH (modified Fisher Grade 4) and a ruptured, 5-mm right PICA aneurysm projecting superomedially. Endovascular coiling was complicated by incomplete aneurysm obliteration and a hypodensity in the PICA territory suspicious for infarct (catheter angiogram and CT image, $\mathbf{D}$ and $\mathbf{E}$ ), and the patient was referred for surgery. The PICA (*) originated from the base of the aneurysm $\left(^{* *}\right)(F)$ and, in addition to coils within the sac of the aneurysm, there was also a tail of coil within the origin of the PICA with associated luminal thrombus and reduced flow. To salvage this artery, PICA reimplantation on the $V_{4}$ segment of the vertebral artery was planned. The neck of the aneurysm and the PICA were clipped with a curved clip, and after temporary clipping of the PICA and transection from the aneurysm, the artery was thrombectomized and reimplanted (G-I). ICG angiography confirmed patency of the reimplanted PICA and no residual filling of the aneurysm. Postoperative CT and angiography confirmed complete occlusion of the aneurysm and patency of the reimplanted PICA (angiograms and CT images, J and K). The patient recovered well from surgery and was discharged 26 days after admission. At the 3-month follow-up evaluation, the patient's left CN VI palsy had partially resolved and her right CN VI palsy had fully resolved (mRS Score 2). 
sign is only observed with ruptured PICA aneurysms and not unruptured PICA aneurysms and that severity of SAH is an important factor affecting a nerve that is not compressed by or even touching the aneurysm. The incidence of CN VI palsy in patients with ruptured PICA aneurysms was 36 times that in patients with ruptured aneurysms in other locations; this comparison controlled for nonspecific effects of SAH generally, raised intracranial pressure, and hydrocephalus. The findings that PICA aneurysm size was not significantly different in patients with or without abducens nerve palsy (the average size in these 2 groups was $4.4 \mathrm{~mm}$ and $5.2 \mathrm{~mm}$, respectively), and that these average sizes were so small suggest that this clinical sign is produced by the hemodynamics of rupture rather than a direct compressive effect, as seen with most other aneurysm-induced cranial neuropathies.

The $18 \%$ incidence of abducens nerve palsy in patients with ruptured PICA aneurysms in our study is comparable to the incidence of oculomotor nerve palsy in patients with PCoA aneurysms, reported at approximately $12 \% .{ }^{8}$ However, the abducens nerve palsy differs from the oculomotor nerve palsy, where the aneurysm clearly impacts the cranial nerve. With PCoA aneurysms, CN III is adjacent to the aneurysm anatomically and is affected by mass effect, with or without aneurysm rupture. ${ }^{2}$ With PICA aneurysms, on the other hand, CN VI is not immediately adjacent to the aneurysm, and therefore an unruptured aneurysm does not exert local mass effect, which explains the absence of palsies in all 40 patients with unruptured PICA aneurysms. Aneurysm size and arterial segment did not differ significantly between those patients with and without a CN VI palsy in the ruptured PICA aneurysm cohort. Instead, the extent of posterior fossa SAH and direction of the aneurysm dome projection were significant. Medially and superiorly projecting PICA aneurysms take aim at Dorello's canal, and direct compressive effects cannot satisfactorily explain the contralateral and bilateral palsies observed in so many of our patients. These findings are consistent with our hypothesis that the jet of ruptured blood flow or subarachnoid blood in Dorello's canal contributed to irritation and dysfunction of CN VI. Evidence exists for this hemodynamic mechanism. In an analysis of 2433 patients with aSAH, Garg et al. found 9 patients with bilateral CN VI palsy, and 3 of these patients had ruptured PICA aneurysms. ${ }^{5}$

Our conclusions about the mechanism of abducens nerve palsy remain speculative. The data regarding thickness of subarachnoid clot and our analysis of dome projection toward the affected Dorello's canal are consistent with our hemodynamic hypothesis. Anatomically, most PICA aneurysms lie well inferior and lateral to the cisternal segment of CN VI, from its origin from the pontomedullary sulcus to its entrance into Dorello's canal, making it unlikely for a small PICA aneurysm to make contact with the nerve. In addition, our review of operative photographs and videos of patients with CN VI palsies did not reveal any direct nerve compression by the aneurysm. Recovery of lateral movement of the affected eye was seen in all patients, although complete recovery was only observed in half of the patients. Therefore, patients can be encouraged to expect recovery over 2-12 months.
One of the limitations of this study, or any future study on the topic, is that the underlying mechanism of nerve injury cannot be studied or measured directly. In addition, this is a retrospective analysis of patients treated surgically by a single surgeon and does not include SAH patients treated with other modalities such as endovascular coiling. Given our relatively small sample size, certain variables could not be added to the multivariate models due to a lack of representation in all groups, and these results need to be confirmed in larger independent case series.

Unlike the compressive cranial nerve palsies associated with other aneurysms that are always ipsilateral to the side of the aneurysm, the abducens nerve palsy in patients with PICA aneurysms can be bilateral or contralateral. Therefore, unlike other compressive palsies, this palsy is not a precise localizing sign with regard to side. Additional radiographic evaluation is necessary with SAH patients presenting with an abducens nerve palsy, and careful examination of both PICAs is mandatory. The association between PICA aneurysm rupture and CN VI palsy is not meant to eliminate the need for diagnostic imaging before embarking on treatment. Rather, it can be considered a new localizing sign that increases our diagnostic acumen at the bedside, focuses the analysis of subsequent diagnostic imaging, and reaffirms the importance of the physical examination, in the tradition of Osler and Cushing.

\section{Conclusions}

Abducens nerve palsy in a patient with aSAH may suggest an underlying ruptured PICA aneurysm. The palsy may be unilateral or bilateral, and its laterality (ipsilateral, contralateral, or bilateral) is dependent on the direction of the aneurysm dome projection and direction of hemorrhage.

\section{References}

1. Da Silva IR: 'Man-in-the-barrel' syndrome with bilateral 6th cranial nerve palsy. Eur Neurol 68:367, 2012

2. Dimopoulos VG, Fountas KN, Feltes CH, Robinson JS, Grigorian AA: Literature review regarding the methodology of assessing third nerve paresis associated with non-ruptured posterior communicating artery aneurysms. Neurosurg Rev 28:256-260, 2005

3. Dupas B, Milea D, Sourour N, LeHoang P: First a third, then a fourth nerve palsy in multiple intracranial aneurysms. Graefes Arch Clin Exp Ophthalmol 244:1539-1541, 2006

4. Fujiwara S, Fujii K, Nishio S, Matsushima T, Fukui M: Oculomotor nerve palsy in patients with cerebral aneurysms. Neurosurg Rev 12:123-132, 1989

5. Garg K, Singh PK, Mahapatra AK, Sharma BS: Bilateral abducens nerve palsy associated with subarachnoid hemorrhage. Br J Neurosurg 28:771-775, 2014

6. Joo W, Yoshioka F, Funaki T, Rhoton AL Jr: Microsurgical anatomy of the abducens nerve. Clin Anat 25:1030-1042, 2012

7. Kołodziej W, Krzeszowiec T, Latka D, Czerwiński K: [Abduction of the eyeballs palsy as a first sign of subarachnoid hemorrhage from ruptured posterior inferior cerebellar artery aneurysm: a case report.] Neurol Neurochir Pol 39:157-162, 2005 (Polish)

8. Koskela E, Laakso A, Kivisaari R, Setälä K, Hijazy F, Hernesniemi J: Eye movement abnormalities after a ruptured intracranial aneurysm. World Neurosurg 83:362-367, 2015 
9. Kshettry VR, Lee JH, Ammirati M: The Dorello canal: historical development, controversies in microsurgical anatomy, and clinical implications. Neurosurg Focus 34(3):E4, 2013

10. Lv X, Ge H, He H, Jiang C, Li Y: Anterior inferior cerebellar artery aneurysms: Segments and results of surgical and endovascular managements. Interv Neuroradiol 22:643-648, 2016

11. Meling TR, Sorteberg W, Bakke SJ, Jacobsen EA, Lane P, Vajkoczy P: Case report: a troublesome ophthalmic artery aneurysm. J Neurol Surg Rep 75:e230-e235, 2014

12. Morioka T, Matsushima T, Yokoyama N, Muratani H, Fujii K, Fukui M: Isolated bilateral abducens nerve palsies caused by the rupture of a vertebral artery aneurysm. J Clin Neuroophthalmol 12:263-267, 1992

13. Nakanishi K, Akai F, Taneda M, Nakao Y: [Four cases of abducens palsy caused by a vascular lesion of the vertebrobasilar system.] No Shinkei Geka 27:19-23, 1999 (Jpn)

14. Park JH, Park SK, Kim TH, Shin JJ, Shin HS, Hwang YS: Anterior communicating artery aneurysm related to visual symptoms. J Korean Neurosurg Soc 46:232-238, 2009

15. Saito H, Nakayama N, Takikawa S, Ushikoshi S, Shinbo D, Kuroda S, et al: [Bilateral abducens nerve palsies in treated cases of subarachnoid hemorrhage.] No Shinkei Geka 40:717-722, 2012 (Jpn)

16. Shukla DP, Bhat DI, Devi BI: Anterior communicating artery aneurysm presenting with vision loss. J Neurosci Rural Pract 4:305-307, 2013

17. Willms JF, Baltsavias G, Burkhardt JK, Ernst S, Tarnutzer
AA: Missed anterior inferior cerebellar artery aneurysm mimicking vestibular neuritis-clues to prevent misdiagnosis. J Stroke Cerebrovasc Dis 25:e231-e232, 2016

18. Zimmer DV: Oculomotor nerve palsy from posterior communicating artery aneurysm. J La State Med Soc 143:22-25, 1991

\section{Disclosures}

The authors report no conflict of interest concerning the materials or methods used in this study or the findings specified in this paper.

\section{Author Contributions}

Conception and design: Lawton, Burkhardt. Acquisition of data: Burkhardt, Winkler, Lasker, Yue. Analysis and interpretation of data: all authors. Drafting the article: Lawton, Burkhardt. Critically revising the article: Lawton, Burkhardt, Winkler, Lasker. Reviewed submitted version of manuscript: Lawton, Burkhardt, Winkler. Approved the final version of the manuscript on behalf of all authors: Lawton. Statistical analysis: Burkhardt, Winkler, Yue. Administrative/technical/material support: Lawton. Study supervision: Lawton.

\section{Correspondence}

Michael T. Lawton, Department of Neurological Surgery, Barrow Neurological Institute, Neurosurgery, 2910 N 3rd Ave., Phoenix, AZ 85013. email: michael.lawton@barrowbrainandspine.com. 